\title{
TERAPIA COMUNITÁRIA INTEGRATIVA: CONSTRUÇÃO DA AUTONOMIA DE FAMÍLIAS DE CRIANÇAS RENAIS
}

\author{
INTEGRATIONAL COMMUNITY THERAPY: CONSTRUCTION OF AUTONOMY OF \\ FAMILIES OF RENAISSABLE CHILDREN
}

\section{Grasiele Cristina Lucietto $^{a \star}$, Rosa Lucia Rocha Ribeiro ${ }^{b^{*}}$, Rondinele Amaral da Silva ${ }^{c^{*}}$, Vagner Ferreira do Nascimento ${ }^{\mathrm{d}^{*}}$}

\author{
gralucietto@gmail.coma ${ }^{\mathrm{a}}$,rosalucia@gmail.com ${ }^{\mathrm{b}}$, rondineleamaral@gmail.comc, vagnerschon@hotmail.com ${ }^{\mathrm{d}}$ \\ Universidade do Estado de Mato Grosso*
}

\section{RESUMO}

Introdução: A Terapia Comunitária Integrativa (TCI) é uma metodologia de cuidado que possibilita aos participantes partilhar experiências e tecer redes sociais, minimizando o sofrimento psíquico. Objetivo: Conhecer as repercussões da TCI para familiares de crianças e adolescentes renais crônicos. Materiais e Métodos: O estudo foi realizado no Ambulatório de Nefrologia Pediátrica de um Hospital Universitário, no município de Cuiabá, Mato Grosso. O material empírico é composto da transcrição das rodas, que foram filmadas, e das anotações da observação participante. Resultados: evidenciaram a TCI como um espaço privilegiado para compartilhar experiências e elevar a autoestima. A TCI tem demonstrado que a troca, a fala, o conhecimento dos sofrimentos alheios tem sido fonte de construção da resiliência. Essa prática viabiliza a formação de redes solidárias e promoção da autonomia. Conclusão: A TCI se mostrou efetiva como cuidado complementar a atenção integral dessas famílias.

Descritores: Terapia; Comunidade; Enfermagem Pediátrica; Doença Crônica; Nefrologia.

Palavras-chave: Terapia; comunidade; enfermagem pediátrica; doença crônica; nefrologia

\begin{abstract}
Introduction: The Integrated Community Therapy (ICT) is a methodology of treatment that allows the participants to share experiences and spin social webs, avoiding psychic suffering. Objective: To know the repercussion of the ICT for relatives from chronic-renals children and teenagers. Materials and Methods: The study was performed at the Pediatric Ambulatory of Nephrology at the Undergraduate Hospital at the city of Cuiabá, Mato Grosso. The ICT rounds were filmed, full-transcribed and, with the anotations of participant observation, composed the empirical material. Results: The theme analysis allowed to recognize the ICT as a privileged space for sharing experiences the upgrade of self-esteem. The ICT has been proving that the exchanging, the talking, the acquaintance of someone else's suffering is the source of construction of resilience. This practice makes possible the shaping of lonely webs and promotion of autonomy. Conclusion: The ICT proved to be effective as complementary care to the integral care of these families.
\end{abstract}

Key-words: Therapy; community; pediatric nursing; chronic disease; nephrology 


\section{INTRODUÇÃO}

A Terapia Comunitária Integrativa (TCI) é um método terapêutico, em que as pessoas se encontram, sentam lado a lado, compondo uma roda, com intuito de compartilhar inquietações, problemas ou dificuldades do cotidiano (individuais e coletivas), bem como alegrias e histórias de superação. Apresenta alta eficácia ao transformar esse compartilhamento de informações/saberes/ histórias em oportunidades de crescimento pessoal, através da valorização dos saberes de cada indivíduo e de sua competência para superação dos desafios diários ${ }^{1}$.

A TCI permite trabalhar com grupos distintos de maneira dinâmica, participativa e reflexiva que oportuniza um ambiente para exposição de problemas e inquietações que repercutirão no diálogo em favor da busca de soluções para os conflitos emanados ${ }^{2}$.

Dessa forma, baseado em resultados obtidos em outros estudos utilizando esse instrumento de cuidado em diversos contextos ${ }^{3,4,5}$ e recentemente com renais crônicos ${ }^{6}$, permite permanecer os investimentos na TCI junto a familiares de crianças com a mesma condição crônica. E considerando a instabilidade no estado de saúde dessas crianças, com novas exigências, transformações constantes e readaptações diversas ${ }^{7}$, o fortalecimento emocional se faz necessário, constituindo uma oportunidade para efetivação da TCI.

Assim, percebendo a importância do cuidado humanizado e integral que deve ser estendido a família dessas crianças, objetivou com o estudo conhecer as repercussões da TCI na construção da autonomia de família de crianças renais.

\section{MÉTODOS}

Trata-se de estudo exploratório, descritivo e de abordagem qualitativa. O estudo foi realizado no Hospital Universitário Júlio Muller em CuiabáMT, junto a familiares de crianças com doença renal crônica. A escolha desse local ocorreu em razão de ser referência em serviço público pediátrico no estado de Mato Grosso e possuir dinâmica e logística favorável para o desenvolvimento do estudo.
Para definição dos sujeitos da pesquisa estabeleceu critérios de inclusão e exclusão. Sendo incluso sujeitos maiores de 18 anos, com vínculo familiar de primeiro grau de crianças em tratamento e que participasse de pelo menos uma roda de TCI. E como critério de exclusão: familiar com convenio privado de saúde ou com vínculo empregatício na instituição.

Mas, foi durante o processo de coleta dos dados que determinou o quantitativo de participantes, com base na exaustividade das informações de interesse, tal como proposto pela saturação amostral ${ }^{8}$.

A coleta dos dados foi realizada no período de novembro de 2012 a fevereiro de 2013, em quatro rodas de TCI promovidas pelos pesquisadores na sala de espera do Ambulatório de Nefrologia Pediátrica dessa instituição, com utilização de diário de campo e filmagem após autorização dos sujeitos da pesquisa.

Após, houve a transcrição na íntegra de todas as rodas de TCI, formando um banco de dados, recebendo tratamento através da análise de conteúdo, do tipo temática. Nessa estratégia, que busca a interpretação cifrada do material de caráter qualitativo, descobrindo os núcleos de sentido que compõem uma comunicação, cuja presença ou frequência tenha significado para o objeto de estudo?

$\mathrm{Na}$ análise, inicialmente procedeu a leitura exaustiva e repetida dos discursos fazendo uma relação interrogativa com elas e reagrupando os temas mais importantes para análise final através de núcleos de sentido mais relevantes.

Este trabalho está vinculado ao projeto matricial de extensão em interface com a pesquisa, "Formação de terapeutas comunitários, assistência à saúde estudantil e pesquisa-ação", cadastrado na Pró-Reitoria de Pesquisa sob o No 272/CAP/2010 e recebeu parecer favorável do Comitê de Ética em Pesquisa do Hospital Universitário Júlio Müller (No 817/CEP-HUJM/2010), em conformidade com a resolução 466/12.

\section{RESULTADOS E DISCUSSÃO}

\section{ESPAÇO DE PARTILHA DE VIVÊNCIAS E PROMOÇÃO DA AUTONOMIA}

A TCI vem se constituindo em um espaço de partilha, em que situações marcadas pela subjeti- 
vidade são trazidas em busca de melhoramento, auxiliando os participantes a se descobrirem capazes de provocar mudanças em sua vida e valorizar os aprendizados do sofrimento ${ }^{5}$. Dessa forma, verifica-se que a TCI pode servir como instrumento para a troca de experiências entre as famílias e os profissionais, uma vez que esta é considerada um recurso de aquecimento e fortalecimento das relações humanas, na construção de redes de apoio social ${ }^{4}$.

Um estudo realizado no Rio de Janeiro ${ }^{10}$ evidenciou como é essencial para as famílias de crianças renais crônicas que os profissionais tenham conhecimento das suas vivências para conseguirem compreender a atual situação em que se encontram. No presente estudo, através da observação das rodas de TCI, notou-se como as pessoas expressavam satisfação em partilhar o processo que sua família vivenciou.

A família pode vivenciar conflitos após o diagnóstico da condição crônica, entre eles o abandono do emprego, gerando desequilíbrio financeiro, incompreensão social e familiar, sobrecarga do cuidador principal e desestruturação familiar. Essas adversidades, oriundas da condição crônica da criança, quando relacionadas com a vida diária, devem ser trabalhadas para evitar o desequilíbrio do sistema familiar, tornando imprescindível para as equipes de saúde aplicar tecnologias de fortalecimento e troca de experiências com essas famílias ${ }^{11}$.

Nos discursos apreendidos os participantes da TCI trouxeram à tona esses tipos de acontecimentos e as repercussões em suas famílias:

Eu querendo estar próximo [da esposa] pra participar da gravidez, estar junto, com tudo o que estava acontecendo. Mas como eu estava longe e tudo isso foi acontecendo, tudo... Até que eu desisti de ficar lá [distante] e vim embora pra cá (Pai de uma criança renal, participante da TCI).

Sabe-se que o adoecimento de um familiar desencadeia alterações nos papeis e estruturas da família, desenvolvendo, desta forma, uma nova dinâmica familiar em que inclui o ato de cuidar. O estado de saúde de cada um tem relação direta no funcionamento da família e que a presença da condição crônica em um membro pode causar desgaste físico e emocional, alterações do cotidiano familiar e necessidade de reorganização de toda a vida familiar ${ }^{10}$. Nos discursos abaixo perce- be-se as mudanças ocorridas no cotidiano desses pais que após a descoberta da doença, também se tornaram cuidadores:

Ia pra casa, voltava. Foi assim três anos, mas labutado mesmo. E eu entrava em desespero! E era praticamente eu sozinha pra correr atrás de tudo. Foi muito difícil, nossa [...] Aí inchava, descompensava, do nada, e tinha que vir pra cá de novo, e internação longa, né (Mãe de uma criança renal, participante da TCI).

Durante a TCI os familiares expuseram suas dificuldades diante da cronicidade do filho, por se verem muitas vezes sozinhos no cuidado, além das diversas viagens realizadas e as internações repetidas e longas. Corroborando com um estu$\mathrm{do}^{12}$ que aponta que a função de cuidar é prestada, na maioria dos casos, pela figura de poucos ou de apenas um único membro da família, chamado de cuidador principal.

Outro discurso, destaca as novas responsabilidades assumidas pelo pai no tratamento do filho, secundarizando suas próprias necessidades e o trabalho.

Eu, quando chega o dia da consulta dele, eu não vou ao meu serviço. No dia da consulta dele eu esqueço tudo, esqueço dor, esqueço firma, esqueço todo mundo pra vim consultar com ele (Pai de uma criança renal, participante da TCI).

É fato que a doença e a hospitalização trazem para as pessoas que a vivenciam a percepção da fragilidade, o desconforto da dor e a insegurança da possível finitude e ameaça ${ }^{10}$. Associado a isso, é comum que o cuidador principal interrompa parte de sua vida social para dedicar-se, exclusivamente, ao cuidado de seu filho e até mesmo abdicar de seu emprego, o que acarreta em uma maior vulnerabilidade para a família ${ }^{7}$.

Foi evidenciada também a aflição de uma mãe logo após receber o diagnóstico do seu filho, por não saber o prognóstico e não ter esclarecimentos suficientes a respeito da nova condição:

Começou o tratamento [...] Eu não entendia nada, era crônico, né? Daí, falava crônico eu já pensava: vai morrer, vai morrer [...] Cada vez que inchava e internava, ficava cada vez pior (Mãe de uma criança renal, participante da TCI).

A comunicação entre profissionais de saúde e cuidadores torna-se fundamental para uma melhor adesão e aceitação da nova condição, 
visto que muitos nunca ouviram acerca da doença e quais são os desafios que necessitarão enfrentar. Torna-se uma ferramenta primordial em todo o processo da condição crônica, desde o diagnóstico, tratamento e hospitalizações.

Nesse momento, delineiam-se algumas inquietações sobre como a criança e a família se instrumentalizam para enfrentarem esse processo ${ }^{13}$. A partilha de experiência oportunizada na TCI possibilitou trazer um conforto e estratégias de como enfrentar essa situação. Observou-se que ao ouvir os depoimentos de outros familiares que conviviam com a condição crônica há mais tempo, os familiares que estavam no inicio deste processo se sentiam mais confiantes e com novas perspectivas.

Esse processo de adaptação das famílias não ocorre estaticamente, podendo passar de um período de controle da situação para outro de descontrole e medo e retornar, novamente, a uma fase de controle, marcadas por diminuição ou exacerbação dos sinais e sintomas da doença ${ }^{12}$.

Muitas vezes, essa instabilidade emocional ocorre, pois existe um pré-julgamento dos profissionais e de outros familiares de que o cuidador é o responsável pelo sucesso ou fracasso do tratamento.

Eu chegava aqui, a doutora olhava pra mim e falava: mãe o que você está fazendo? Entendeu? Eu falava: nada, doutora nada! E você não entende direito. No começo, você acha que ela está te colocando culpa, sabe? (Mãe de uma criança renal, participante da TCI).

Nessa perspectiva, é atribuído aos familiares a função de cuidador principal, em sua maioria, de forma espontânea. No entanto, essa incumbência acarreta uma sensação de insegurança e responsabilização, visto que geralmente os familiares não recebem treinamento ou preparo adequados para realizar esse novo papel. A utilização de termos técnicos utilizados pelos profissionais de saúde dificulta a compreensão do tratamento, tornando-se um ponto negativo para o cumprimento das atividades propostas. Como consequência, o cuidador passa a se omitir, sente coagido a calar-se, ouvir e responder estritamente o que o profissional deseja saber ${ }^{12}$.

A família, portanto, não pode ser considerada como cumpridora de determinações dos profissionais de saúde, mas necessita de esclarecimentos para se tornar autônoma no cuidado ${ }^{14}$.
Destaca-se entre os discursos a experiência de uma mãe sobre a dificuldade para se adequar ao cuidado no início do tratamento, o desânimo por ser responsabilizada pelo cuidado e o sentimento de culpa quando esse não apresentava sucesso.

Aí, em casa, eu dava alguma coisa [alimento]. Aí eu falava pra minha mãe: mãe, o menino está inchando... Ela falava: o que você deu pra ele? Tudo caía em cima de mim, tudo a culpada era eu... Então, tinha dia que eu desanimava (Mãe de uma criança renal, participante da TCI).

Como foi difícil. Tinha hora que dava vontade de falar assim: eu não vou dar mais medicação, vou largar! Eu chegava nesse ponto, entendeu? (Mãe de uma criança renal, participante da TCI).

Apesar das dificuldades enfrentadas no início de um tratamento, com o passar do tempo e com apoio de tecnologias do cuidado (como neste estudo, a TCI), a família consegue ser instrumentalizada e se preparar para assumir o controle da situação.

A família conseguirá perceber que a doença crônica é administrável, que pode ser passível de convivência e de um futuro para a criança, sendo capazes de lidar com a mesma com mais segurança e desempenhando o cuidado da melhor forma possível ${ }^{13}$.

Eu faço aquele controle em casa com o xixi dele. E se eu dou um refrigerante, no outro dia eu já vejo a diferença, já sei que está perdendo proteína (Mãe de uma criança renal, participante da TCI).

Essa efetividade no cuidado esta relacionada à forma como a Enfermagem se relaciona e empodera essa família para o cuidado. A TCI, portanto, se mostra funcional para os profissionais assim como para os usuários.

Desta forma, fica evidente que a assistência prestada à criança ou adolescente adoecidos cronicamente deve contemplar ações que sejam capazes de cuidar de suas carências físicas, emocionais e sociais, incluindo e considerando a participação da família ${ }^{12}$.

Destaca-se, também, outro momento nessa roda de TCI, conforme nota de observação abaixo:

$A$ avó de uma criança, a qual não se manifestou durante todo o decorrer da TCI, se mostrava muito chorosa após o seu encerramento. Timidamente, se dirigiu às terapeutas e, ainda apreensiva e emocionada, partilhou seus medos sobre o tratamento do 
neto e sobre o impacto desta condição crônica para a vida de seu filho, o pai da criança. A terapeuta a acolheu, ouviu atentamente e contou-lhe sobre ofenômeno da formação da pérola. Disse que a pérola se forma a partir da agressão à ostra por um pequeno grão de areia que a penetra e que, como mecanismo de proteção, a envolve com uma substância (o nácar) e, desse processo, a pérola, tão apreciada e valorizada, é produzida. Com o processo de adoecimento acontece algo similar, as dificuldades decorrentes das alterações no cotidiano, geram sofrimento, angústia, incertezas, mas ao mesmo tempo vão sendo ressignificadas resultando algum aprendizado, aprimoramento pessoal, emocional e resiliência, mostrando a possibilidade de se fortalecer e retirar algo de positivo na situação de adoecimento (Nota de Observação).

Com essa analogia, a terapeuta valorizou a avó da criança, seu processo de aprender com as dificuldades, aprimoramento pessoal ou resiliência, mostrando a ela que compreendia e valorizava o seu sofrimento e que, ainda assim, havia algo de positivo na situação. Da mesma forma, seu filho estaria se transformando, tornando-se um homem mais maduro e melhor.

Sobre o fenômeno da resiliência, Camarotti15 afirma que, muitas vezes, a carência pode gerar competência. Resiliência, para a autora, é sofrimento que gera capacitação e fortalecimento. A prática da TCI tem demonstrado que a troca, a fala, o conhecimento dos sofrimentos alheios tem sido fonte de construção da resiliência e, esta vivência em serviços de saúde, viabiliza um processo para formação de redes solidárias, canalizando sofrimentos e trazendo à tona aqueles que estavam ocultos.

\section{CONCLUSÃO}

Ao término do estudo, observou-se a efetividade da TCI como tecnologia de cuidado complementar e atenção integral às famílias que estão vivenciando uma condição crônica. As perdas pelo processo de adoecimento podem ocorrer em qualquer fase da vida, contudo, na infância, estas se tornam mais intensas, visto que repercutem tanto no desenvolvimento da criança, quanto em mudanças no comportamento e cotidiano dos fa- miliares. Nesse sentido, espaços de partilhas auxiliam no processo de resiliência, tanto individualmente como no coletivo.

Os momentos de partilha permitiram observar a vivência do outro, sua capacidade de lidar e superar os sofrimentos, angústias e limitações. $\mathrm{O}$ que tornou essas famílias reconhecedoras da sua própria capacidade de superar o sofrimento.

Além disso, houve oportunidade de exteriorizar problemas e assim possibilitar o alivio de diversas dores. Ainda que o participante não tenha verbalizado durante a roda de TCI, a contribuição foi expressiva, por ter oportunizado reflexões espelhadas no exemplo do outro. E ao reconhecer essas oportunidades de construção de rede de apoio, vê-se necessário novos estudos, a fim de elucidar novas cenários para aplicação da TCI.

\section{REFERÊNCIAS}

1. Barreto AP, Lazarte R. Uma Introdução à Terapia Comunitária Integrativa: conceito, bases teóricas e método. In: Ferreira Filha MO, Lazarte R, Dias MD. Terapia comunitária integrativa: uma construção coletiva do conhecimento. João Pessoa: Editora Universitária da UFPB, 2013.

2. Carvalho MAP, Dias MD, Miranda FAN, Ferreira Filha MO. Contribuições da terapia comunitária integrativa para usuários dos Centros de Atenção Psicossocial (CAPS): do isolamento à sociabilidade libertadora. Cad. Saúde Pública. 2013 out [acesso em: 12 dez 2016]; 29(10):2028-2038. Disponível em: http://www.scielo.br/ pdf/csp/v29n10/a19v29n10.pdf

3. Silva GT, Costa ALRC, Buzzeli CP, Maruyama SA, Ribeiro RLR. Significados da participação em roda de terapia comunitária para os estudantes de uma universidade pública. Cienc Cuid Saúde. 2012 Jul/Set [acesso em: 12 nov 2016]; 11(3):445-453. Disponível em: http://periodicos.uem.br/ojs/index.php/CiencCuidSaude/article/ view/14967/pdf

4. Carício MR et al. Terapia Comunitária: um encontro que transforma o jeito de ver e conduzir a vida. In: Ferreira Filha MO, Lazarte R, Dias MD. Terapia comunitária integrativa: uma construção coletiva do conhecimento. João Pessoa: Editora Universitária da UFPB, 2013.

5. Braga LAV et al. Terapia Comunitária e Resiliência: história de mulheres. In: Ferreira Filha MO, Lazarte R, Dias MD. Terapia comunitária integrativa: uma construção coletiva do conhecimento. João Pessoa: Editora Universitária da UFPB, 2013.

6. Melo OS, Ribeiro LRR, Costa ALRC, Urel DR. Repercussões da terapia comunitária integrativa nas pessoas doen- 
tes renais durante sessão de hemodiálise. J. res.: fundam. Care [Internet]. 2015 abr/jun [acesso em: 10 jan 2017]; 7(2):2200-2214. Disponível em: http://www.redalyc.org/ pdf/5057/505750946002.pdf

7. Gondim KM, Carvalho ZMF. Sentimentos das mães de crianças com paralisia cerebral à luz da teoria de Mishel. Esc Anna Nery. 2012 jan/mar [acesso em: 12 nov 2016]; 16(1): 11-6. Disponível em: http://www.scielo.br/scielo. php?script=sci_abstract\&p

\section{Como citar este artigo:}

Lucietto GC, Ribeiro RLR, Silva RA, Nascimento VF. Terapia comunitária integrativa: construção da autonomia de famílias de crianças renais. Rev. Aten. Saúde. 2018;16(58):57-62. 